\title{
DESMONTAGEM: FOTOGRAFIA E PROCESSO FICCIONAL
}

\author{
Amanda M. P. Leite ${ }^{1}$ \\ "O real precisa ser ficcionalizado para ser \\ pensado"
}

(RANCIÈRE, 2009, p. 58)

O que nos impulsiona a narrar algo? Costumo lançar esta pergunta nas ações que realizo como fotógrafa, pesquisadora e professora. A fotografia carrega certa magia, nos captura, faz com que desejemos narrar diversos temas, nos provoca a perceber (cada um a seu modo) a coisa em si, a imagem pensante - "este poder comum da igualdade das inteligências liga indivíduos, faz que eles intercambiem suas aventuras intelectuais, à medida que os mantem separados uns dos outros, igualmente capazes de utilizar o poder de todos para traçar seu caminho próprio" (RANCIÉRE, 2012, p. 20-21).

O que move o fotógrafo continua sendo os segredos de cada fotografia, seus trançados, sua verba ficcional e fragmentada. Aquilo que se dá visível e que sobrevive ao tempo. É a convergência da fábula em linhas, traços e cores. Se a fotografia é capaz de tecer memórias daquilo que somos e daquilo que nos sustenta, talvez seja a hora de propor a desmontagem da fotografia - lidar com o deslocamento do olhar, com a composição fotográfica e seu processo ficcional. Movimentos que devagarinho compõe este texto e desde o início escapam da ideia representativa do real para quem sabe ver de quantos remendos a fotografia contemporânea é tecida.

\section{Desmontagem}

O conceito de desmontagem é cunhado pela professora Ileana Diéguez e nos convida a pensar sobre a questão da teatralidade com a noção de performatividade. Caballero sugere que na prática atores e atrizes dialoguem com o público sobre a concepção da obra e seu processo criativo. Na desmontagem, atores/artistas assumem o risco e procuram fundamentar seu trabalho num diálogo direto com o público interessado. $\mathrm{O}$ artista (e neste caso pensaremos na figura do fotógrafo) mostra as pesquisas e as influências do trabalho. Neste diálogo compartilha as buscas, o pensamento envolvido na composição da cena/fotografia como uma espécie de "evento artístico pedagógico"”.

Esta reflexão possibilita pensar a fotografia enquanto espaço aberto ao entrecruzamento da Arte e da Vida. A fotografia aparece como uma cadeia complexa de práticas artísticas e requer um pensamento mais denso sobre sua própria desmontagem. Pensar sobre o processo de desmontagem das representações é procurar a presença ausente (do fotógrafo e de outros eus) nas capturas produzidas. Ao invés de mostrar apenas o resultado final em uma exposição fotográfica, importa partilhar com aquele que vê as etapas de trabalho, de criação, de composição, num processo teórico-artesanal, sem separação entre teoria e prática. A desmontagem fotográfica permite colocar a imagem suscetível às observações humanas, a atravessamentos, significações intelectuais, culturais, sentimentais, etc. É potente por promover trocas conceituais e poéticas, por gerar experimentações e diferentes processos criativos, por estimular aprendizagens a partir da desmontagem da própria estrutura da imagem.

\footnotetext{
1 Doutora em Educação. Fotógrafa. Professora da Universidade Federal do Tocantins (UFT). E-mail: amandaleite@uft.edu.br. Blog: 〈http://paraverepensar.blogspot.com.br〉.

${ }^{2}$ Dieguez. Ileana. DESMONTAGEM CÊNICA. Rascunhos Uberlândia v. 1 n. 1 p. 6. jan.|jun. 2014.
} 
$\mathrm{Na}$ arena do Teatro, a ideia de representação é legitimada. Colocá-la em suspensão para indagar se a verdade representada é um tipo de ilusão, faz com que o sentido do teatro se expanda. Sabemos que no território da fotografia esse prélio ganha outras dimensões. Revelar que uma fotografia é montagem pode arruinar a veracidade do fato exposto na foto.

A proposta de Caballero é desnudar a representação enquanto "verdade" e ver o que dela desponta. Gosto desta ideia, a de despir o conceito de representação contido na fotografia. Acredito na necessidade da desmontagem fotográfica. Parece haver aí um apelo para que o fotógrafo se mostre, para que voltemos à origem das ideias, dos esboços, dos roteiros, das pesquisas fotográficas... Quem é a presença oculta por trás da captura e qual a sua relação com a cena capturada e o contexto imortalizado? É possível desmontar a relação tão bem consolidada entre criador e criatura?

A fotografia foge de uma imitação do real ainda que queira documentá-lo. Não se trata tão somente de perceber uma presença simbólica, semiótica e representacional contida na fotografia, mas atingir outros textos: visuais, corpóreos, sonoros, ficcionais... Por si só, a fotografia evoca que a plateia testemunhe um acontecimento (real e/ou ficcional) e transcenda sua limitação provisória. Caballero (2010, p. 139) assinala que a representação pode ser entendida ainda como "desvio, [...] quando na cena teatral se toma o texto como pretexto e não se deseja representar personagens, mas a própria condição de atores" - do mesmo modo que na fotografia, pode se tomar a trama fotográfica como um posicionamento crítico, político, ético, estético do fotógrafo - "e sem dúvida, pela maneira como falam, jogam ou ironizam reconhecemos que estamos diante de um jogo de papéis" - assim também o é na composição fotográfica onde encontramos o jogo de espectros imagéticos que, muitas vezes, identifica o interesse de seu criador - o fotógrafo.

Ao problematizar a desmontagem da fotografia exponho a vontade de encontrar hibridizações, rasgões contidos na imagem contemporânea e questionar o território da arte, da política, da poética, da ética e da estética fotográfica. Ao desnudar a fotografia, espero descobrir exposições do imaginário, frutos do desejo (individual e/ou coletivo), o desclausuramento de presenças que não necessariamente tenham sido capturadas com um fim artístico. $\mathrm{Na}$ desmontagem coloco em dúvida a arte, seus saberes e discursos para extrapolar a estrutura da fotografia e conhecer outros modos de produzir imagens. É o caráter paradoxal da fotografia que interessa de imediato para além de sua materialidade. É a probabilidade de movimentos intermináveis que retém a atenção. Busco encontrar meios de pausar o gesto do click para pensar sobre o ato fotográfico em si e o processo criativo.

A desmontagem da fotografia é um dispositivo aberto e a ação do fotógrafo que se expõe com a obra pode revelar as paixões, os motivos que estimularam a produção, os caminhos da pesquisa, à construção da narrativa e o contágio com diferentes áreas e modos de pensar e compor a própria imagem. Uma ação que embaralha e exibe conflitos, fragilidades, negociações do percurso ao mesmo tempo em que anuncia o projeto do artista. A desmontagem possibilita ainda ativar ideias sobre algo, indagar, interromper o silêncio de um tema, fazer circular pensamentos junto a fotografias contemporâneas e práticas artísticas. Um movimento desterritorializado e experimental, atravessado por singularidades, criação e pesquisa, independente de associar a fotografia a uma espécie de documento ou ficção.

Uma coisa é propor a desmontagem convocando o fotógrafo a revelar-se junto com a imagem (suas anotações, percursos, provocações...). Outra coisa é considerar que a composição fotográfica é feita de (des)montagem para promover sentidos e sensações diversas no fotógrafo e no leitor. Neste caso, pensar se dá também pelo processo, pela composição que não exclui as fronteiras da fotografia, nem demarca espaços internos e externos, mas sugere relação entre eles na intenção de deslocar os elementos da imagem para outros lugares. Um convite à 
emancipação do espectador e sua capacidade de ver, pensar e falar a partir daquilo que vê como aponta Rancière (2012).

\section{Composição fotográfica}

O tempo que dura o olhar sobre uma fotografia tem a ver com o modo como compomos a imagem? Esta questão nos leva a dois caminhos. O primeiro corresponde às escolhas técnicas que o fotógrafo pode adotar para compor uma fotografia, exemplo: regras dos terços, perspectiva, enquadramento, composição simétrica, radial, horizontal, vertical, diagonal, sombras, reflexos, sobreposição, entre outras. O objetivo é fazer com que a técnica estimule o espectador passar mais tempo mirando a imagem. Não se trata apenas de uma fotografia esteticamente bem executada, mas de uma fotografia que conecte o espectador a pensamentos, sentidos, emoções. Independentemente se o motivo fotografado aparece em primeiro plano ou como elemento secundário desde que a fotografia esteja equilibrada e forme uma composição instigante de se mirar.

O segundo caminho é subjetivo, está conectado as inquietações do fotógrafo, a maneira como irá organizar os elementos de sua narrativa, seja por formulações poéticas, enquadramentos (des)harmônicos, (des)contrução de ideias, deslocamentos conceituais. A composição fotográfica considera o modo como à imagem é pensada e concebida. Muitas vezes vem desprendida de técnica, despreocupada com profundidade de campo, posição dos elementos, plano de enquadramento, etc. O que faz da fotografia algo interessante não é o tipo de técnica ou câmera utilizada, mas como compomos fotograficamente um motivo. A concepção de uma imagem liga-se à imaginação (do fotógrafo e do espectador), não há "certo" e "errado", há impacto visual e potencialidade inventiva.

\section{Processo ficcional}

Desconfio de abordagens que tomam a fotografia tão somente como documento do real. A fotografia sugere a construção ficcional de narrativas. Realidades são inventadas e dispostas ao olhar curioso que confunde, nega, afirma, questiona e embaralha aquilo que vê. Entre recortes temporais e espaciais, entre coisas que são visíveis e dizíveis e aquelas que não conseguimos ver ou dizer, podemos propor relações entre realidade e ficção. Num jogo experimental de formas, palavras e ruídos podemos compor aquilo que Rancière (2009, p. 17) denomina como "práticas estéticas" ou "visibilidade das práticas estéticas da arte, do lugar que ocupam, do que fazem, no que diz respeito ao comum".

A ficção provoca rupturas pela própria forma. Se o uso da imagem ficcional sugerir um estilo singular para o ver e o pensar, poderemos perceber que a fotografia produz conhecimento e ensina por ela mesma. Pensar é um movimento quase artesanal que admite as etapas de montagem e desmontagem da fotografia para transformar a realidade. A imagem ficcional é pensada no espaço da fronteira, do "entre", por isso é potente e pode promover a $e$-ducação do olhar pontuada por Masschelein (2008). Ao contrário de restringir leituras e não possibilitar que a ficção habite o campo da fotografia, o exercício fotográfico (descentralizado) articula o ver e o pensar.

O fotógrafo cria, recria, inventa, compõe ficções. As ficções podem se aproximar do real, mas não deixam de ser ficcionais. A fotografia está sempre aberta, a espera de leituras, conexões, (des)continuidades relacionadas ao cotidiano do espectador. O desafio está na interface entre realidade e ficção. A emancipação do sujeito e a transformação do presente pode se dar na/pela ficção. 
Para concluir, mas continuar pensando sobre o encontro da fotografia com a ficção trago fragmentos da série Sonoridades ${ }^{3}$, produzida por mim em 2016. Um exercício localizado no campo da fotografia experimental. O convite abaixo dá pistas sobre a composição e as questões que inspiraram a série. Boa leitura!
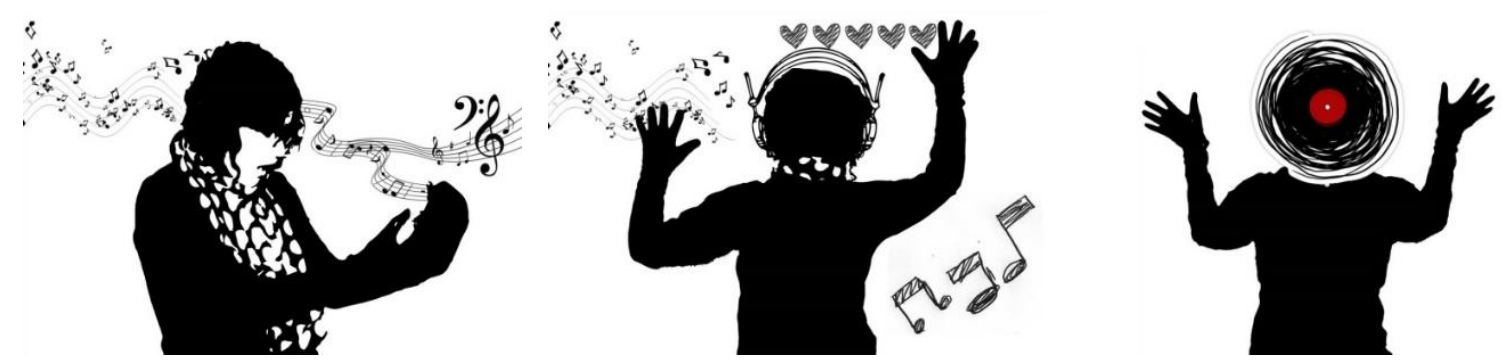

Que sonoridade nos move? Sons da rotina provocam (an)dança, movimento, interrupção... É possível pensar com o corpo? Como se faz para dançar com as ondas sonoras cotidianas? Estamos diante de um pensamento rítmico que se permite contagiar, (re)inventar os nossos clichês e perguntar: somos capazes de desenhar uma cartografia sonora da nossa singularidade? A partir do autorretrato procuro aquilo que não posso ver (quem sabe sentir, ser atravessada). As fotografias nos convidam a desgarrar-se do externo para perceber coisas que se alojam em movimento. Um modo de pensar (e sentir) que supõe uma autonomia nômade, que se deixa contaminar ou viajar sem sair do lugar. Para onde nos levam estas sonoridades?

\section{Referências}

CABALlERO, Ileana Dièguez. Cenários expandidos. (Re)presentações, teatralidades e performatividades. Urdimento - Revista de Estudos em Artes Cênicas, Universidade do Estado de Santa Catarina, Programa de Pós-Graduação em Teatro, v. 1, n. 15 (out. 2010) Florianópolis: UDESC/CEART.

CABALLERO, Ileana Dièguez. Desmontagem Cênica. Revista Rascunhos, Uberlândia, v. 1, n. 1, p. 5-12, jan./jun. 2014.

MASSCHELIEN, Jan. E-ducando o olhar; a necessidade de uma pedagogia pobre. Educação \& Realidade, v. 33, n. 1, p. 35-48, 2008.

RANCIÈRE, Jacques. O espectador emancipado. Tradução Ivone C. Benedetti. São Paulo: Editora WMF Martins Fontes, 2012.

RANCIÈRE, Jacques. A partilha do sensível: estética e política. Tradução Mônica Costa Netto. São Paulo: Eixo experimental org. Editora 34, 2009 (2. ed.).

\footnotetext{
${ }^{3}$ Veja a série completa em: 〈http://paraverepensar.blogspot.com.br〉.
} 